\title{
Inhibitory tagging in visual search can be found if search stimuli remain visible
}

\author{
YUJI TAKEDA and AKIHIRO YAGI \\ Kwansei Gakuin University, Nishinomiya, Hyogo, Japan
}

\begin{abstract}
Klein (1988) reported that inhibitory tagging (i.e., inhibition of return in visual search) made reaction times for the detection of small probes increase at locations where there had previously been rejected items in serial visual search. It is reasonable that the attended and rejected locations are inhibited. However, subsequent studies did not support Klein's idea. In these studies, inhibitory tagging was tested after removing the items from the search tasks. The paradigms in these studies were not appropriate for testing an object-based inhibitory effect because the objects (i.e., items) were removed from the display. In the present study, we found that evidence of inhibitory tagging could be observed only when the items of the search tasks were maintained until the responses for the small probes were made. This appeared to be an object-based effect.
\end{abstract}

When a person searches a visual field for a target that is defined by a simple visual feature (e.g., a vertical line target among horizontal line distractors), it can be detected efficiently and effortlessly, irrespective of the set size of the search items. However, if a target is defined by spatial arrangement (e.g., a " $T$ " target among " $L$ " distractors), the detection performance is inefficient (Treisman \& Gelade, 1980). Efficient processing for some arrays (e.g., a "C" target among "O" distractors) becomes ineffective when the characteristics of target and distractor are exchanged (i.e., an "O" target among " $\mathrm{C}$ " distractors). This is called search asymmetry (Treisman \& Gormican, 1988; Treisman \& Souther, 1985).

Many models of visual search assume that the arrays which elicit efficient search are processed in parallel and that those which elicit inefficient search are processed serially (Treisman \& Gelade, 1980; Wolfe, Cave, \& Franzel, 1989; but see also Duncan \& Humphreys, 1989). Serial processing involves deployments of attention from item to item, serially. Preventing the return of attention to previously visited items can improve the efficiency of search by preventing ineffective reexaminations of rejected distractors (Klein, 1988). Klein proposed that returning attention is inhibited by inhibitory tagging. The inhibitory tagging hypothesis is based on Posner's inhibition of return (see Posner \& Cohen, 1984).

Klein (1988) demonstrated inhibitory tagging by first requiring his subjects to perform either an efficient par-

\footnotetext{
We thank J. M. Wolfe, R. M. Klein, T. S. Horowitz, and T. Sanocki for useful comments on an earlier version. This research was supported by the original Industrial Technology Research and Development Promotion program from the New Energy and Industrial Technology Development Organization (NEDO) of Japan (8F-022-1). We are grateful to Mary Flaherty for English phraseology. Correspondence should be addressed to Y. Takeda, Kumada Group, Human Informatics Department, National Institute of Bioscience and Human Technology, 1-1 Higashi, Tsukuba, Ibaraki, 305 Japan (e-mail: ytakeda@nibh.go.jp).
}

allel search or an inefficient serial search. After each response in the search task, a luminance detection task was given. The luminance probe was presented at a location that had been occupied by a search item (on probe) or a previously empty location (off probe). Klein used the difference in reaction time (RT) between on probe and off probe as a measure of inhibitory tagging and other factors (e.g., forward masking) that might be operating when a stimulus is prevented from appearing in the location of a previous stimulus. Because he found that this difference was greater in serial than in parallel search (a difference unlikely to be attributed to masking in his design), he concluded that inhibitory tagging was operating in the serial search task. This interpretation was reinforced by the further finding that the inhibitory effect (i.e., onoff difference in the serial search task minus that in the parallel search task) was greater on target-absent than on target-present trials. Because search performance was assumed to be self terminating if the target was detected, on the average, half of the items on target-present trials should be inhibited, whereas all the items were presumed to have been examined on target-absent trials.

Wolfe and Pokorny (1990) examined the inhibitory tagging hypothesis by replicating Klein's paradigm (see also Wolfe et al., 1989). However, they did not find evidence for inhibitory tagging. In their study, the on-off difference in the parallel search task and that in the serial search task were equally inhibited. When, in an unpublished study, Pontefract and Klein attempted to replicate the original result, they also failed (cited in Klein \& Taylor, 1994).

The items of the search task were removed from the display before the luminance detection probe was presented in those studies. In other words, the presentation of the luminance probe was separated from the search task. Recent studies have pointed out the importance of objectbased attention in the inhibition of return (IOR; Abrams 
\& Dobkin, 1994; Tipper, Driver, \& Weaver, 1991; Tipper, Weaver, Jerreat, \& Burak, 1994; but see also Müller \& von Mühlenen, 1996). When one considers the importance of objects in IOR, perhaps the removal of the search array before the probe is presented may remove the inhibitory tags. Tipper et al. (1994) predicted that the removal of the objects would remove the object-based inhibition in Klein's (1988) paradigm. Suppose that inhibition is attached to object files (Kahneman, Treisman, \& Gibbs, 1992) and that when the array is removed, the object file representation is cleared. In that case, inhibitory tagging might be observed if the search array were not removed.

In Experiment 1, inhibitory tagging was reexamined using Klein's (1988) original paradigm. This paradigm might separate the subject's set for the luminance detection task from the search task. In contrast, the presentation of the search items on the luminance detection task might prevent the subject's set from involving objectbased inhibition and provide new evidence for inhibitory tagging. In Experiments 2 and 3, search items were presented until the offset of the luminance detection probe. Finally, in Experiment 4, we eliminated a potential alternative explanation for the results of Experiments 2 and 3.

\section{EXPERIMENT 1}

\section{Method}

Subjects. Twenty subjects $18-27$ years old participated in each experiment (Experiments 1-4). They were naive as to the purpose of the experiments.

Stimuli. All stimuli were generated and displayed on an AVTachistoscope system (IWATSU ISEL IS-701A) equipped with a P31 phosphor. The stimuli were presented in a $5^{\circ} \times 5^{\circ}$ display field with green dots $\left(34.7 \mathrm{~cd} / \mathrm{m}^{2}\right)$. The subjects observed the stimuli at a $78-\mathrm{cm}$ viewing distance, in darkness. Each trial began with the presentation of a fixation point ( $a$ "+") at the center of the display field (see Figure 1). The fixation point subtended $0.8^{\circ}$ of visual angle. After $1 \mathrm{sec}$, a search stimulus was presented. The search stimuli consisted of circles and arcs. The diameters of these items subtended $0.8^{\circ}$ of visual angle. One eighth of the circle was cut as a gap to constitute each arc. The location of the gap was presented at ran-

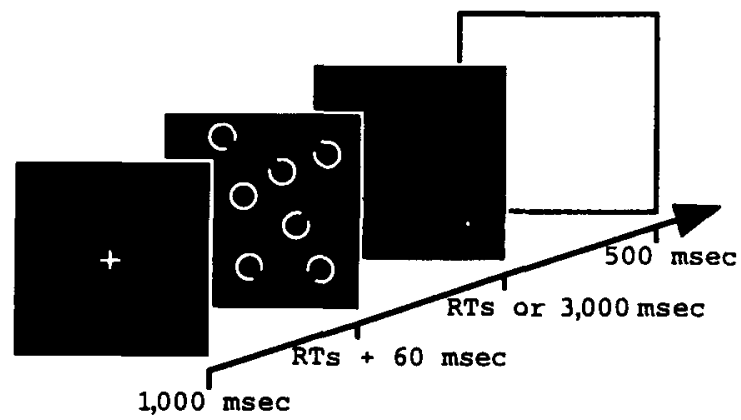

Figure 1. An example of the array of stimuli in Experiment 1. The fixation point, the search items, and the probe were displayed with green dots on a black background. The probe is drawn larger than actual size (which was a single pixel). In this example, the target item of the $O$ among $C$ s search task and the probe are presented. dom. Two different search tasks were given, one with the arc as the target and circles as the distractors ( $\mathrm{C}$ among Os task), and the other with the circle as the target and arcs as the distractors ( $\mathrm{O}$ among $\mathrm{Cs}$ task). The former is processed more efficiently than the latter (Treisman \& Gormican, 1988). In half of the trials, the target was presented. On the other half, the target was absent. Set sizes of four and eight items were used at random. These items were arranged randomly with some restriction to prevent overlap.

In the search task, $60 \mathrm{msec}$ after a response was given, a luminance detection probe consisting of a single pixel was presented on $50 \%$ of the trials. When the luminance probe was absent, a blank display was presented. On half of the trials in which the luminance detection probe was presented, the probe was displayed at a location where there had previously been a distractor item (on probe). On the remaining trials, the probe was displayed at the previously empty location (off probe). The probe was not presented at the target location. When the subject responded, this stage was terminated immediately. If no probe was presented, this stage lasted for $3 \mathrm{sec}$. After the luminance detection stage, a filled stimulus (i.e., when the display was occupied by green dots) was presented for $500 \mathrm{msec}$. The next trial followed immediately after the termination of the filled stimulus.

Tasks. In the search task, the subjects responded by pressing one of two keys with their right index fingers or middle fingers, depending on whether the display contained the target. In the luminance detection task, they were required to respond to the presentation of the luminance detection probe by pressing a key with their left index fingers (go/no go task). The subjects were required to respond to each stimulus in the search task and the luminance detection task as fast as possible. No feedback was given to the subjects.

The subjects were tested both in the $\mathrm{O}$ among $\mathrm{Cs}$ task and the $\mathrm{C}$ among Os task. Each task contained three blocks, and each block consisted of 80 trials. The order of the $\mathrm{O}$ among $\mathrm{Cs}$ and $\mathrm{C}$ among Os tasks varied between subjects.

The $\mathrm{C}$ among $\mathrm{Os}$ condition provided a baseline for assessing the effect of factors other than inhibitory tagging, such as masking effects. An increase in the on-off difference for the $\mathrm{O}$ among $\mathrm{Cs}$ condition relative to the $\mathrm{C}$ among $\mathrm{Os}$ condition provides evidence of the inhibitory tagging effect.

\section{Results and Discussion}

Mean RTs for the search tasks are shown in Figure 2. The mean error rate in these tasks was $1.6 \%$. A slope was defined as an increase in RT per item in the search task. The slopes in the $\mathrm{O}$ among Cs tasks were steeper than those in the $\mathrm{C}$ among Os tasks. In the $\mathrm{O}$ among Cs tasks, the slope for the target-absent trials was approximately twice as steep as that for the target-present trials. The slopes were analyzed with a two-factor analysis of variance (ANOVA, target-present vs. target-absent; $\mathrm{O}$ among $\mathrm{Cs}$ vs. C among Os). The main effect of target presence versus absence $\left[F(1,19)=11.77, M S_{\mathrm{e}}=552.8, p<.01\right]$, the main effect of the search types $\left[F(1,19)=107.97, M S_{\mathrm{e}}=\right.$ $408.8, p<.01]$, and the interaction of these factors $\left[F(1,19)=17.25, M S_{\mathrm{e}}=193.1, p<.01\right]$ were significant. The slopes of the $\mathrm{C}$ among Os task were not very efficient (target present, $8.73 \mathrm{msec} / \mathrm{item}$; target absent, $13.86 \mathrm{msec} /$ item). However, these slopes indicated that the $\mathrm{O}$ among $\mathrm{Cs}$ tasks were processed less efficiently than the $\mathrm{C}$ among Os tasks.

In the luminance detection task, the probe was presented at a distractor location (on probe) or at an empty location (off probe). The differences of probe RTs between on probe and off probe were calculated as the measures 

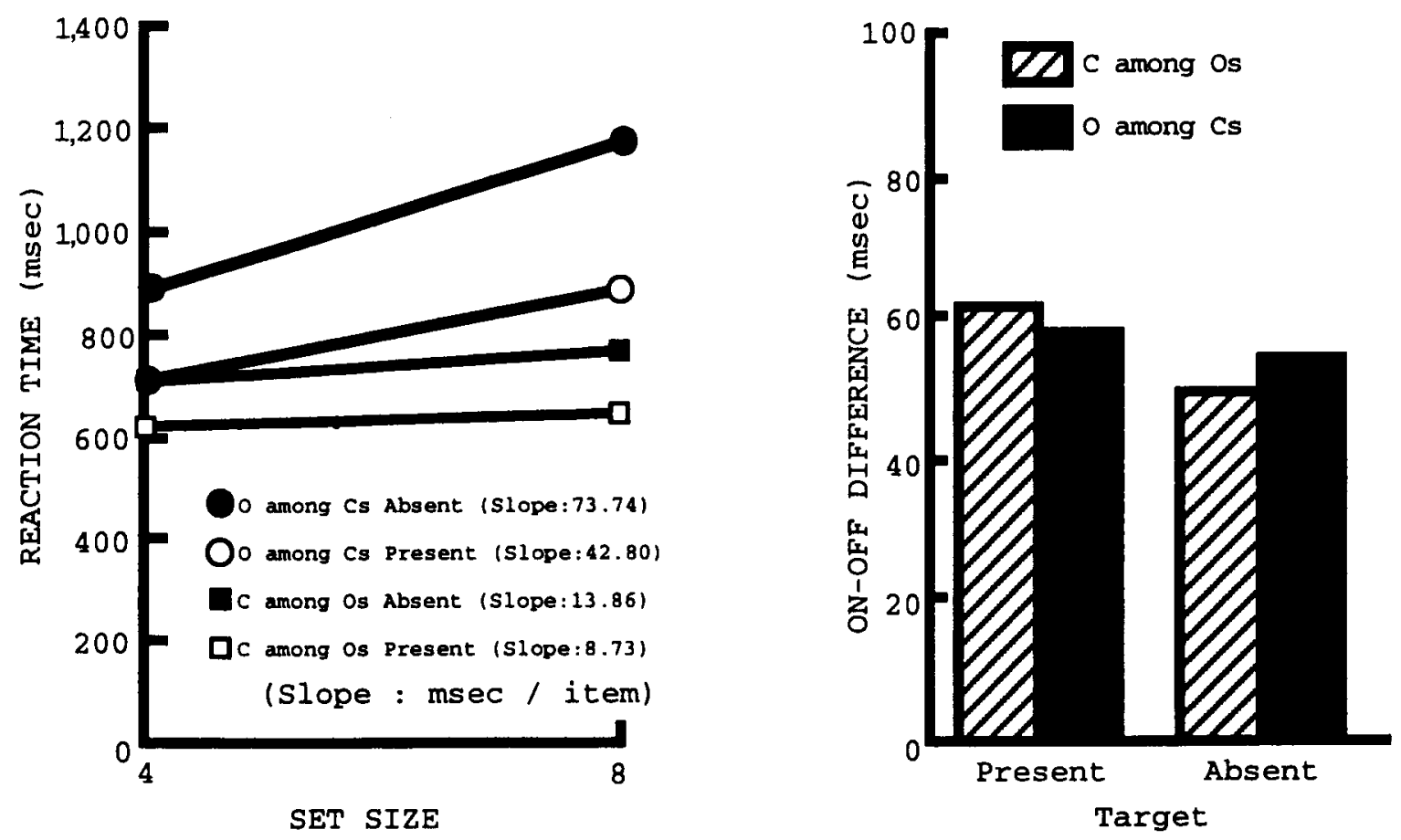

Figure 2. The results of Experiment 1. The left panel indicates reaction times for target-present and target-absent trials in two different search tasks. The right panel indicates the on-off difference in the luminance detection tasks.

collapsed across the set size conditions of the search tasks. The on-off differences are shown in Figure 2 (details of the results are shown in the Appendix). The miss rate in these tasks was $0.8 \%$, and the false alarm rate was $1.0 \%$. A two-factor ANOVA (target present vs. target absent; $\mathrm{O}$ among Cs vs. C among Os) yielded no significant effect. Statistical analyses of the miss rate and the false alarm rate also yielded no significant effects.

The difference between on- and off-probe RTs is a measure of inhibitory tagging. A larger difference for inefficient search for Os among Cs than for efficient $\mathrm{Cs}$ among Os would be evidence for a role of inhibitory tagging in visual search. However, the results of this experiment did not support the hypothesis of inhibitory tagging. These results were similar to those of Pontefract and Klein (cited in Klein \& Taylor, 1994) and Wolfe and Pokorny (1990).

As noted in the introduction, if the tags were attached to object files, inhibitory tagging might have been removed with the removal of the search array. In Experiment 2 , we examined this possibility by using a paradigm in which the items of the search task remained until a response in the luminance detection task was made.

\section{EXPERIMENT 2}

\section{Method}

The stimuli and tasks were the same as those of Experiment 1, except that the items of the search task remained until onset of a response in the luminance detection task (see Figure 3).

\section{Results and Discussion}

One subject was dropped from further analysis, because the subject's error (miss) rate was more than $30 \%$ in the luminance detection tasks.

Mean RTs for the search tasks are shown in Figure 4. The mean error rate in these tasks was $1.7 \%$. The slopes were analyzed with a two-factor ANOVA (target present vs. target absent; $\mathrm{O}$ among $\mathrm{Cs}$ vs. $\mathrm{C}$ among $\mathrm{Os}$ ). The main effect of target presence versus absence $[F(1,18)=$ $\left.4.85, M S_{\mathrm{e}}=462.7, p<.05\right]$, the main effect of the search types $\left[F(1,18)=74.14, M S_{\mathrm{e}}=412.2, p<.01\right]$, and the

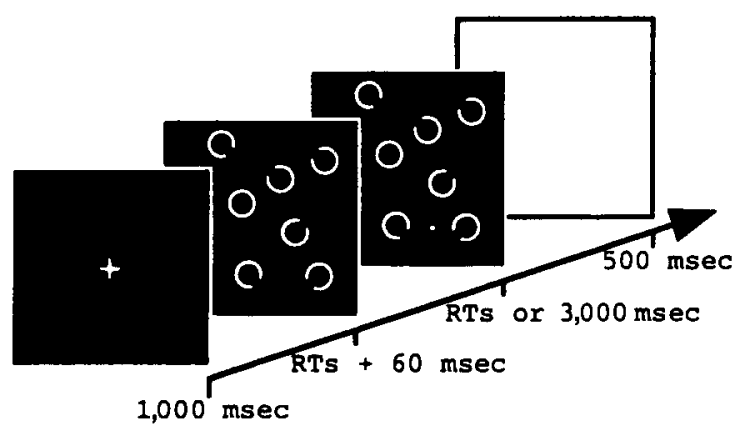

Figure 3. An example of the array of stimuli in Experiment 2. In this example, the target item of the $O$ among $C$ s search task and the probe (i.e., the off-probe condition) are presented. In the on-probe condition, the probe was presented at the center of the distractor. In the off-probe condition, the mean distance between the probe and the nearest edge of item subtended approximately $0.6^{\circ}$. 

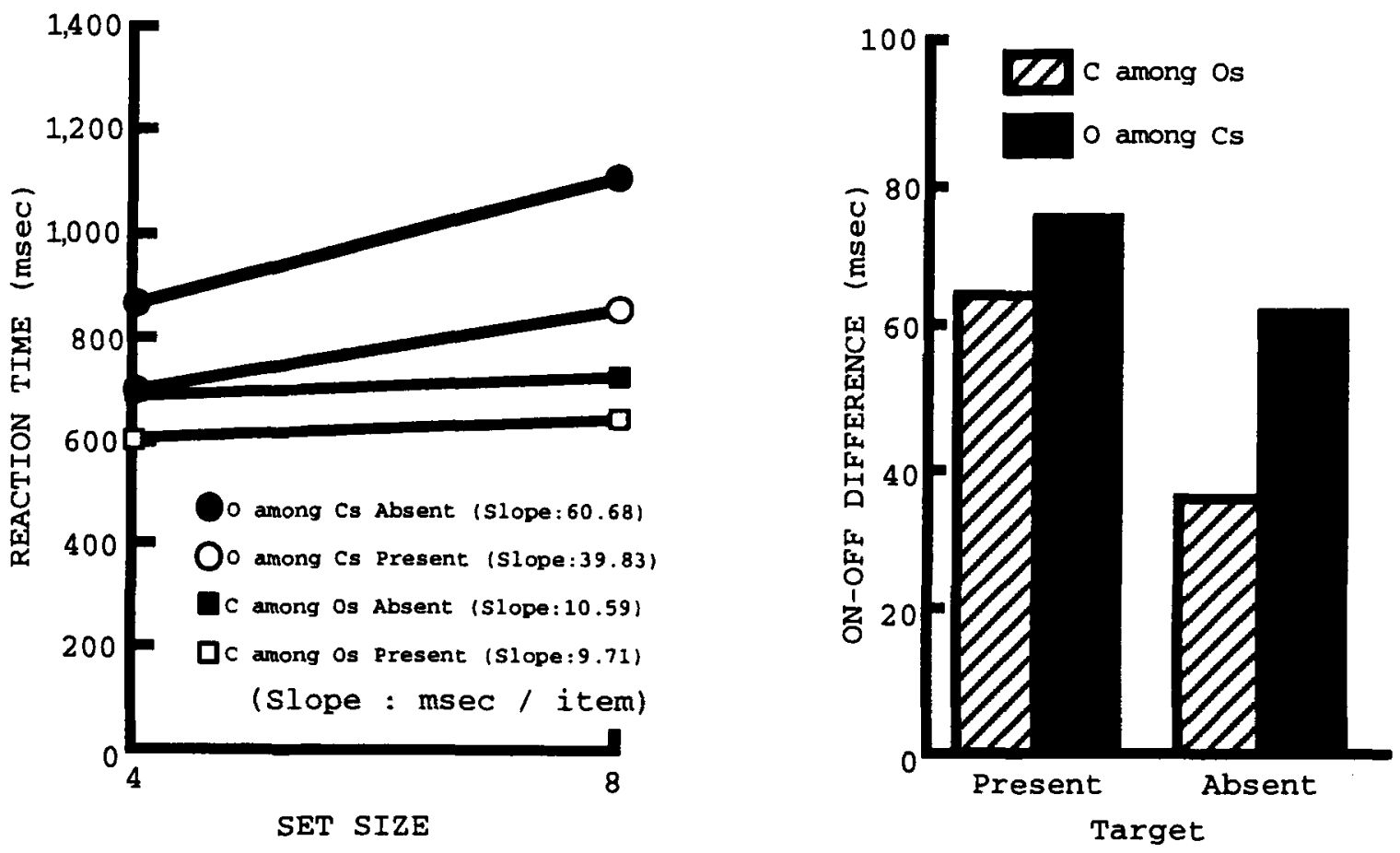

Figure 4. The results of Experiment 2. The left panel indicates reaction times for target-present and target-absent trials in two different search tasks. The right panel indicates the on-off difference in the luminance detection tasks.

interaction of these factors $\left[F(1,18)=11.06, M S_{\mathrm{e}}=\right.$ $171.2, p<.01]$ were all significant. The results for the slopes were similar to those in Experiment 1.

In the luminance detection task, the differences between on probe and off probe were calculated with the same method as in Experiment 1. The on-off differences are shown in Figure 4. The miss rate in these tasks was $1.5 \%$, and the false alarm rate was $1.3 \%$. A two-factor ANOVA (target present vs. target absent; $O$ among Cs vs. $\mathrm{C}$ among Os) yielded significant effects of the target presence versus target absence $\left[F(1,18)=6.45, M S_{\mathrm{e}}=1,246\right.$, $p<.05]$ and for the search types $\left[F(1,18)=4.45, M S_{\mathrm{e}}=\right.$ $1,526, p<.05]$. Statistical analyses of the miss rate and the false alarm rate yielded no significant effects.

The main effect of the search types indicates that the items on $\mathrm{O}$ among Cs tasks were more inhibited than those on the $\mathrm{C}$ among Os tasks. This effect was predicted by the inhibitory tagging hypothesis, because more items should have been inhibited in the inefficient search. The main effect of the target (present vs. absent) means that some inhibitory effects other than tagging were larger on targetpresent conditions than on target-absent conditions. In this research, it is unclear what kind of processing on target-present trials increased the baseline of the probe detection RTs, which were unrelated to the search task types. This effect was not predicted by inhibitory tagging processing, although it was not contrary to the existence of the inhibitory tagging.

The interaction between the target factor and the search factor was not significant. However, the inhibitory tag- ging effect (on-off $\mathrm{O}$ among $\mathrm{Cs}$ minus on-off $\mathrm{C}$ among Os) on target-absent trials was larger than on target-present trials ( $26.6 \mathrm{msec}$ vs. $11.2 \mathrm{msec}$ ). This was also predicted by inhibitory tagging processing, because if search were serial and self-terminating, inhibition would have been tagged to every item on the target-absent trials, whereas this was not the case for target-present arrays.

These results indicate that inhibitory tagging occurred in the inefficient (i.e., serial) search task. However the effect in this experiment might be specific to the particular items (i.e., circles and arcs). In Experiment 3, we examined the effect of the inhibitory tagging with different types of search items.

\section{EXPERIMENT 3}

\section{Method}

The stimuli and task were the same as those in Experiment 2, except that the items of the search were a circle and a Q-like shape. The $O$ and $Q$ items were also used in Klein's (1988) original study. The line of the Q-like item subtended $0.3^{\circ}$ of visual angle. It was already known that the $\mathrm{O}$ among $\mathrm{Qs}$ search would be more inefficient than the Q among Os search (Treisman \& Souther, 1985).

\section{Results and Discussion}

Mean RTs for the search tasks are shown in Figure 5. The mean error rate in these tasks was $2.0 \%$. The slopes were analyzed with a two-factor ANOVA (target present vs. target absent; $O$ among Qs vs. Q among Os). The main effect of target presence versus target absence $\left[F(1,19)=32.54, M S_{\mathrm{e}}=344.9, p<.01\right]$, the main effect 

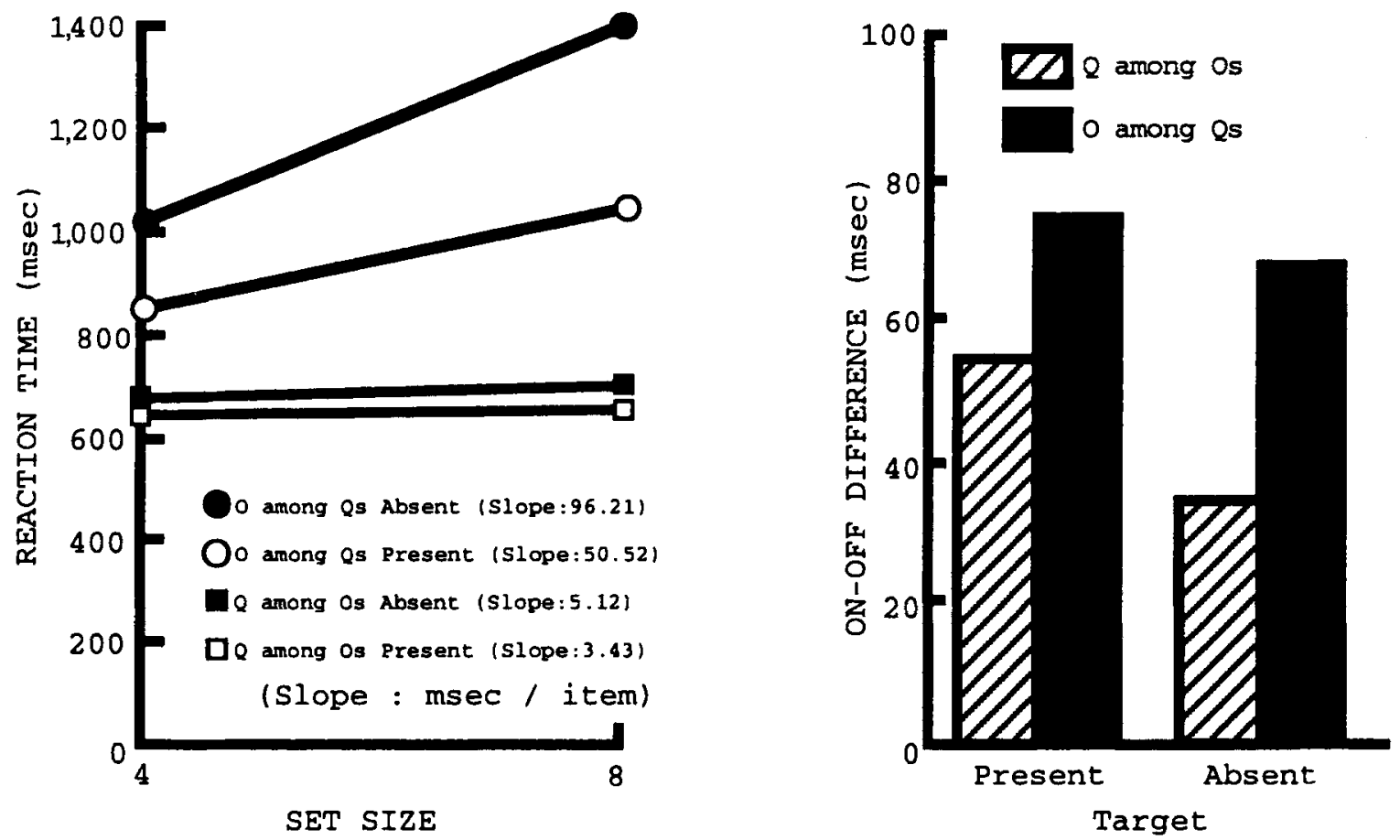

Figure 5. The results of Experiment 3. The left panel indicates reaction times for target-present and target-absent trials in two different search tasks. The right panel indicates the on-off difference in the luminance detection tasks.

of search types $\left[F(1,19)=115.17, M S_{\mathrm{e}}=829, p<.01\right]$, and the interaction of these factors $[F(1,19)=38.08$, $\left.M S_{\mathrm{e}}=254.2, p<.01\right]$ were all significant. In this experiment, the $O$ among Qs search was processed more inefficiently than the $\mathrm{Q}$ among Os search. These results were similar to those of the previous experiments.

In the luminance detection task, the differences between on and off probe were calculated by the same method as in the previous experiments. The on-off differences are shown in Figure 5 (right). The miss rate in these tasks was $1.5 \%$, and the false alarm rate was $1.3 \%$. A two-factor ANOVA (target present vs. target absent; O among Qs vs. Q among Os) yielded a significant effect of search $\left[F(1,19)=8.64, M S_{\mathrm{e}}=1,638, p<.01\right]$. Statistical analyses of the miss rate and the false alarm rate yielded no significant effects. These results were similar to those of Experiment 2. Evidence for inhibitory tagging was shown in the two experiments by employing two types of search elements.

In Experiments 2 and 3, the factor of set size was collapsed as the measure of the luminance detection tasks. The effects of the set size in luminance detection tasks are shown in Figure 6 . The data from Experiments 2 and 3 were collapsed, and the factor of target present and target absent was also collapsed. A two-factor ANOVA (set size 4 versus set size 8 ; efficient search vs. inefficient search) yielded a main effect of search type $[F(1,38)=$ 13.1, $\left.M S_{\mathrm{e}}=1,556, p<.001\right]$, but the factor of set size and the interaction were not significant. These results in- dicate that the strength of the inhibitory tags for set size four and that for set size eight were equivalent on each item.

The results of Experiments 2 and 3 indicate that the RTs for the probes surrounded by previously attended items (Cs in Experiment 2 and Qs in Experiment 3) were longer than those surrounded by unattended items (Os in both experiments). These patterns of RTs were predicted by the inhibitory tagging hypothesis. However, it remained necessary to examine the conspicuity of the probe surrounded by each item $(\mathrm{C}, \mathrm{Q}$, or $\mathrm{O})$ in order to rule out the possibility that the differences of RTs for probes between efficient and inefficient searches might be caused by the shape of the items (e.g., lateral masking). If the conspicuity of the probe surrounded by a C (or a Q) item was less than that surrounded by an $\mathrm{O}$ item without search tasks, the results from Experiments 2 and 3 would not support the inhibitory tagging hypothesis. In Experiment 4 , we examined the conspicuity of probes without search tasks.

\section{EXPERIMENT 4}

\section{Method}

The array of stimuli was very similar to that in Experiments 2 and 3. Each trial began with the presentation of a fixation point. After $1 \mathrm{sec}$, a homogeneous array of $\mathrm{Os}, \mathrm{Cs}$, or Qs (the same as the display of the target-absent trial in Experiments 2 and 3) was presented without any search tasks. Types of items (Os, Cs, and Qs) and the set sizes of 4 and 8 items were presented at random. During half of the trials, a single pixel probe was presented $1 \mathrm{sec}$ after the 


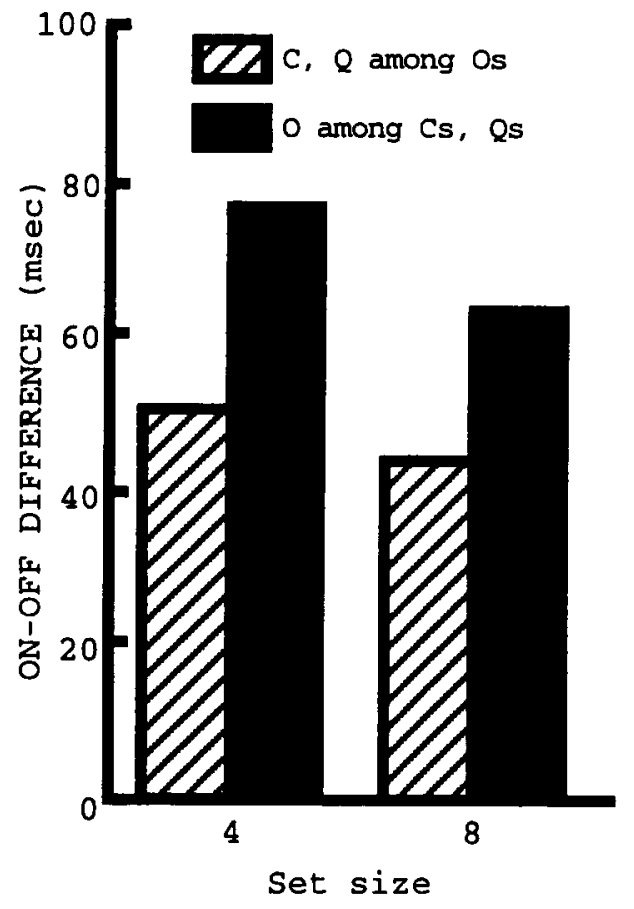

Figure 6. The on-off differences for each set size, collapsed across Experiments 2 and 3. The factors of target present and target absent were also collapsed.

onset of the homogeneous array (the mean RTs for search tasks in Experiments 2 and 3 were approximately $1 \mathrm{sec}$ ). In the luminance detection task, the subjects were required to respond to the presentation of a probe. The conditions in these tasks were the same as those in the previous experiment (on and off probe). If the response was input, a filled square was presented immediately. If no response was input, the square was presented $4 \mathrm{sec}$ after the onset of the homogeneous array. After $500 \mathrm{msec}$, the next trial began.

\section{Results and Discussion}

The differences of probe RTs between on probe and off probe were calculated as the measures collapsed across the set size conditions of the homogeneous array. The on-off differences are shown in Figure 7 . The miss rate in these tasks was $0.6 \%$, and the false alarm rate was $0.5 \%$. A single-factor ANOVA (Os vs. Cs vs. Qs) yielded no significant effect $\left[F(2,38)=0.008, M S_{\mathrm{e}}=1,044, p>\right.$ .95]. Statistical analyses of the miss rate and the false alarm rate yielded no significant effect. These results indicate that there were no differences in probe conspicuity between $\mathrm{O}, \mathrm{C}$, and $\mathrm{Q}$. Thus, the results of Experiments 2 and 3 could be explained by inhibitory tagging.

\section{GENERAL DISCUSSION}

Experiment 1, conducted according to Klein's (1988) paradigm, showed no evidence for inhibitory tagging. However, in Experiments 2 and 3, evidence for inhibitory tagging was obtained when we modified Klein's paradigm by leaving the search stimuli visible. In Experi- ment 4, we showed that the results of Experiments 2 and 3 were not caused by the effects of the probe conspicuity.

We suggest that inhibitory tagging was not seen in Experiment 1 because any tagging vanished along with stimuli. Inhibitory tagging could aid search by diverting attention away from previously rejected distractors. This makes sense when one is viewing a scene. However, if one scene is changed into another, a new important signal might occupy the location of a previously rejected distractor. In this case, inhibition would interfere with the search of a new scene. Thus, it would be reasonable that inhibitory tagging disappears when the inhibited stimuli disappear.

Klein (1988) reported that inhibitory tagging effects occurred, in spite of the removal of the items. However, these inhibitory effects were not observed in his subsequent experiment in which the same paradigm was used (Pontefract \& Klein, cited in Klein \& Taylor, 1994). The inconsistency of the results from these two experiments might have been caused by the difference in the brightness of the oscilloscope. It is possible that the oscilloscope was brighter in Klein (1988) than in his subsequent study (R. M. Klein, personal communication, April 2, 1998). The higher intensity makes the search arrays more persistent. The persistence of items may produce inhibitory effects similar to those in Experiments 2 and 3 in the present study.

Inhibitory tagging on the target-absent trials should be twice as great as on the target-present trials. In our study, the mean differences of the target-absent trial was approximately twice as much as those of the target-present trial, but statistical analyses yielded no significant effect. Al-

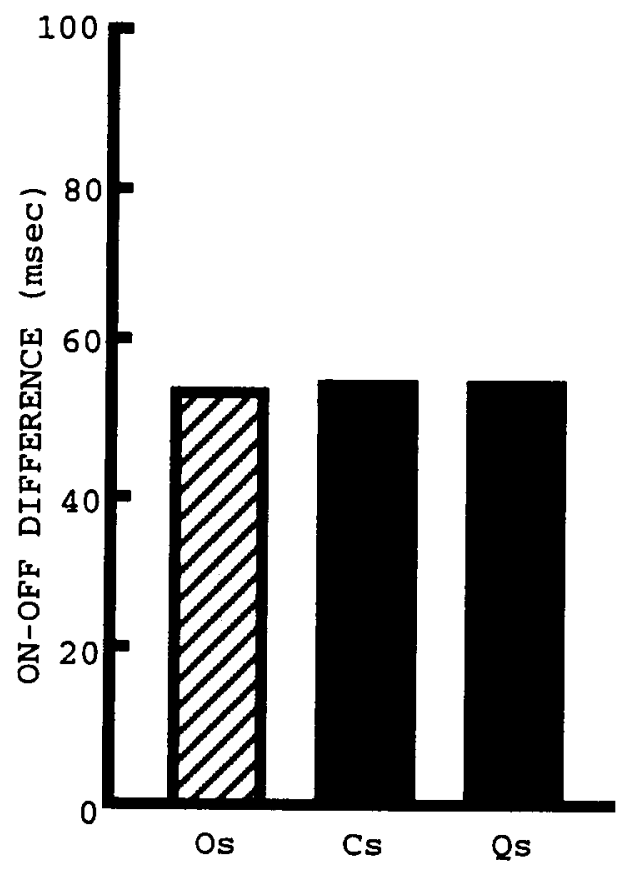

Figure 7. The results of Experiment 4. 
though not statistically significant, the deviation of the probe detection RTs in the target-present trial was very large in the within-subjects analysis. On the average, half the items were tagged in the target-present trial. However, the number of tagged items was unsettled in each trial. Therefore, this result might not be significant.

In Experiments 2 and 3, the baselines of the on-off differences were lower in the target-absent condition than in the target-present condition, which was unrelated to search efficiency. This result was not a prediction of inhibitory tagging and was very puzzling. This baseline variation could be explained if there were an advantage for probe detection at the gazing location. When subjects responded to search tasks, they might have attended and gazed at the target location on the target-present conditions, whereas they might have attended and gazed at one of the search distractor locations on the target-absent conditions. In the on-probe condition, the probe was presented at one of the distractor locations, but not at the target locations. If probe detection at the gazing location and/or object location was easier than at other locations, probe detection would be easy when the probe is presented at the gazing location on the target-absent conditions. Therefore, on the average, the baselines in the targetabsent condition might be lower than those in the targetpresent condition.

The mean duration between the onset of search array and the onset of the luminance probe in inefficient search trials was larger than that in efficient search trials. Moreover, the processing of inefficient search might need more mental resources than those for efficient search. However, the results from the factor of set size eliminate this possibility. Although the mean duration was larger in the set size 8 condition than in the set size 4 condition, and more resources were needed in the set size 8 condition than the set size 4 condition, there was no effect of set size. Therefore, we consider that the duration and mental resources did not affect the detection of the luminance probe.

Recently, Horowitz and Wolfe (1998) suggested that visual memory is not necessary for an inefficient visual search. Inhibitory tagging needs some sort of visual memory, because the tagged location must be stored for at least $1,000 \mathrm{msec}$. The inconsistency between these two studies might be explained by the difference in strategies. In the study of Horowitz and Wolfe, the search items were relocated randomly every $111 \mathrm{msec}$. They found that the RT $\times$ set size slope in this search was less steep than in the static items search in the target-present trials. In their relocate condition, inhibitory tagging was eliminated at every relocation, because the scene was changed every $111 \mathrm{msec}$. Therefore, it is possible that the subjects had to use another strategy. One of the important functions of inhibitory tagging is the termination of the visual searches in the target-absent trials. In the target-absent trials of Horowitz and Wolfe, the slopes in the random conditions were much less steep than those in the static con- ditions. The slopes of target-absent trials were approximately twice as steep as those of target-present trials in their static conditions. In the random condition, however, the slopes in the target-absent trials were not as large as those in the target-present trials. Therefore, we suggest that the subjects had to use a different strategy in the target-absent trials in the random conditions. One possible strategy is that the subjects responded "no target is presented" when the target could not be found for a certain period.

Wolfe and Pokorny (1990) conducted experiments similar to Experiment 1 of the present study (i.e., the items of the search task were removed from the display before the luminance detection probe was presented). They observed longer RTs in the on-probe conditions than in the off-probe conditions, but no differences between the efficient search and the inefficient search (similar to Experiment 1 of the present study). They mentioned that the inhibitory effect (i.e., the on probes were slower than the off probes) found in their study could be attributed to forward masking. In our study, the RTs for the on-probe condition were longer than these in the off-probe condition, which was unrelated to the search efficiency (Experiments 1,2 , and 3 ). These results indicate that the on-off differences consisted of the effects of inhibitory tagging and masking. However, the following factors in our study could not be explained by the forward masking effect: (1) The on-off differences in the inefficient search (i.e., $\mathrm{O}$ among $\mathrm{Cs}$ and $\mathrm{O}$ among $\mathrm{Qs}$ ) were greater than those in the efficient search (i.e., $\mathrm{C}$ among $\mathrm{Os}$ and $\mathrm{Q}$ among $\mathrm{Os \text {). }}$ (2) The effect of inhibitory tagging in the target-absent trial was approximately twice as much as in the targetpresent trials. (However, the statistical analyses did not yield a significant effect.) And (3), the effect of inhibitory tagging was not dependent on the sort of search item. Therefore, the results of this study could well be explained by the inhibitory tagging hypothesis. These results support the proposal that inhibitory tagging operates during inefficient search and also that maintenance of the search array is important for maintenance of the inhibitory tags. Recently, converging evidence for this proposal has been provided by a study of oculomotor behavior during search of complex scenes (Klein \& MacInnes, 1999).

\section{REFERENCES}

Abrams, R. A., \& Dobkin, R. S. (1994). Inhibition of return: Effects of attentional cuing on eye movement latencies. Journal of Experimental Psychology: Human Perception \& Performance, 20, 467-477.

DunCAN, J., \& Humphreys, G. W. (1989). Visual search and stimulus similarity. Psychological Review, 96, 433-458.

Horowitz, T. S., \& Wolfe, J. M. (1998). Visual search has no memory. Nature, 394, 575-577.

Kahneman, D., Treisman, A., \& GibBs, B. J. (1992). The reviewing of object files: Object-specific integration of information. Cognitive Psychology, 24, 175-219.

KLEIN, R. M. (1988). Inhibitory tagging system facilitates visual search. Nature, 334, 430-431. 
KLEIN, R. M., \& MACINNES, W. J. (1999). Inhibition of return is foraging facilitator in visual search. Psychological Science, 10, 346-352.

KLEIN, R. M., \& TAYLOR, T. L. (1994). Categories of cognitive inhibition with reference to attention. In D. Dagenbach \& T. H. Carr (Eds.), Inhibitory processes in attention, memory, and language (pp. 113150). San Diego: Academic Press.

Müller, H. J., \& von MüHLENEN, A. (1996). Attentional tracking and inhibition of return in dynamic displays. Perception \& Psychophysics, 58, 224-249.

Posner, M. I., \& Cohen, Y. (1984). Components of attention. In H. Bouma \& D. G. Bowhuis (Eds.), Attention and performance X: Control of language processes (pp. 531-556). Hillsdale, NJ: Erlbaum.

TiPPER, S. P., Driver, J., \& Weaver, B. (1991). Object-centered inhibition of return of visual attention. Quarterly Journal of Experimental Psychology, 43A, 289-298.

Tipper, S. P., Weaver, B., Jerreat, L. M., \& Burak, A. L. (1994).
Object-based and environment-based inhibition of return of visual attention. Journal of Experimental Psychology: Human Perception \& Performance, 20, 478-499.

Treisman, A. M., \& Gelade, G. (1980). A feature integration theory of perception. Cognitive Psychology, 12, 97-136.

Treisman, A. M., \& Gormican, S. (1988). Feature analysis in early vision: Evidence from search asymmetries. Psychological Review, 95, 15-48.

Treisman, A. M., \& Souther, J. (1985). Search asymmetry: A diagnostic for preattentive processing of separable features. Journal of Experimental Psychology: General, 114, 285-310.

Wolfe, J. M., Cave, K. R., \& Franzel, S. L. (1989). Guided search: An alternative to the feature integration model for visual search. Journal of Experimental Psychology: Human Perception \& Performance, 15, $419-433$.

Wolfe, J. M., \& PoKorny, C. W. (1990). Inhibitory tagging in visual search: A failure to replicate. Perception \& Psychophysics, 48, 357-362.

\section{APPENDIX \\ Details of the Data From the Probe Detection Tasks}

Experiments 1 and 2

\begin{tabular}{|c|c|c|c|c|c|c|c|c|}
\hline \multirow[b]{3}{*}{ Set Size } & \multicolumn{4}{|c|}{ C Target } & \multicolumn{4}{|c|}{ O Target } \\
\hline & \multicolumn{2}{|c|}{ Present } & \multicolumn{2}{|c|}{ Absent } & \multicolumn{2}{|c|}{ Present } & \multicolumn{2}{|c|}{ Absent } \\
\hline & On & Off & On & Off & On & Off & On & Off \\
\hline \multicolumn{9}{|c|}{ Experiment 1} \\
\hline 4 & 405.7 & 339.6 & 417.7 & 364.8 & 401.5 & 339.9 & 416.6 & 356.0 \\
\hline 8 & 405.4 & 349.6 & 406.6 & 361.1 & 407.2 & 352.4 & 428.4 & 380.0 \\
\hline \multicolumn{9}{|c|}{ Experiment 2} \\
\hline 4 & 377.6 & 308.9 & 363.7 & 324.5 & 409.7 & 315.6 & 388.7 & 321.2 \\
\hline 8 & 365.0 & 305.3 & 365.0 & 332.3 & 396.9 & 340.2 & 397.7 & 340.0 \\
\hline \multicolumn{9}{|c|}{ Experiment 3} \\
\hline & \multicolumn{4}{|c|}{ Q Target } & \multicolumn{4}{|c|}{ O Target } \\
\hline & \multicolumn{2}{|c|}{ Present } & \multicolumn{2}{|c|}{ Absent } & \multicolumn{2}{|c|}{ Present } & \multicolumn{2}{|c|}{ Absent } \\
\hline Set Size & On & Off & On & Off & On & Off & On & Off \\
\hline 4 & 372.1 & 314.7 & 363.5 & 323.4 & 396.3 & 313.4 & 398.1 & 336.4 \\
\hline 8 & 370.0 & 318.0 & 351.9 & 322.9 & 391.3 & 325.8 & 414.7 & 339.8 \\
\hline \multicolumn{9}{|c|}{ Experiment 4} \\
\hline & \multicolumn{2}{|c|}{ Cs } & \multicolumn{2}{|c|}{ Qs } & \multicolumn{2}{|c|}{ Os } & & \\
\hline Set Size & On & Off & On & Off & On & Off & & \\
\hline $\begin{array}{l}4 \\
8\end{array}$ & 407.3 & 369.9 & 432.4 & 369.2 & 406.7 & 371.1 & & \\
\hline 8 & 437.0 & 363.0 & 426.3 & 378.6 & 435.7 & 362.4 & & \\
\hline
\end{tabular}

(Manuscript received January 15, 1998 ; revision accepted for publication July 21,1999 .) 